\title{
How Does the Use of Facial Cosmetics Influence Social Perceptions of Women in the Recruitment Process?
}

\author{
Kristiane Tommerup ${ }^{1}$, Adrian Furnham ${ }^{2 *}$ \\ ${ }^{1}$ Department of Clinical, Educational, and Health Psychology, University College London, London, UK \\ ${ }^{2}$ Norwegian Business School (BI), Olso, Norway \\ Email: *a.furnham@ud.ac.uk
}

How to cite this paper: Tommerup, K., \& Furnham, A. (2019). How Does the Use of Facial Cosmetics Influence Social Perceptions of Women in the Recruitment Process? Psychology, 10, 481-499. https://doi.org/10.4236/psych.2019.104032

Received: February 3, 2019

Accepted: March 11, 2019

Published: March 14, 2019

Copyright () 2019 by author(s) and Scientific Research Publishing Inc. This work is licensed under the Creative Commons Attribution International License (CC BY 4.0).

http://creativecommons.org/licenses/by/4.0/

\begin{abstract}
The current study aimed to investigate the influence of facial cosmetics on perceptions of female applicants. In all, 286 participants were asked to evaluate the resume of a photographed female based on capability, earning potential, popularity, and hire-ability for either a "sales assistant" or "sales manager" role. It was hypothesized that perceived attractiveness and use of professional facial cosmetics would increase all ratings of professional competence. Further, facial cosmetics would be more advantageous for less attractive applicants and managerial applicants. The results supported these hypotheses, demonstrating that the use of professional facial cosmetics improved ratings of competence for female applicants. However, this enhancement was greater for less attractive female applicants and managerial applicants. Implications and limitations are discussed.
\end{abstract}

\section{Keywords}

Cosmetics, Face, Attractiveness, Job Applicants, Selection

\section{Introduction}

Although rational recruitment decisions should reflect the qualifications and competencies of an applicant, recent literature suggests that a female's use of facial cosmetics can influence these decisions (Etcoff, Stock, Haley, Vickery, \& House, 2011; Nash, Fieldman, Hussey, Lévêque, \& Pineau, 2006). Facial cosmetics are commonly used in organizational settings, particularly during the recruitment process (Britton, 2012; Leslie, 2013). However, the effect of facial cosmetics in these practices has received little empirical focus. As such, the pre- 
sent study set out to uncover how the use of facial cosmetics can influence people's perceptions of females within recruitment procedures.

\subsection{The Halo Effect}

Physically attractive individuals are often perceived favourably on an array of psychological and personality traits (Dion et al., 1972) described as the: "What is Beautiful is Good" stereotype. In various classic experiments, participants judged physically attractive faces as more intelligent, healthy, sociable, and morally upright. Additionally, attractive subjects were believed to hold more secure and prestigious jobs (Davies et al., 2008; Dipboye, Fromkin, \& Wiback, 1975; Eagly, Ashmore, Makhijani, \& Longo, 1991; Lucker, Beane, \& Helmreich, 1981). Moreover, the strength of halo effect is dependent upon on the personality trait under assessment, as social traits are further enhanced by beauty than intellectual traits (Eagly et al., 1991). From this point forward, research began to investigate the halo effect on judgements of both intellectual and social traits specific to social context.

The current paper places focus on the halo effect in organizational settings. The first piece of information available to recruitment personnel is often a resume or online profile (Jobvite, 2015). Recent surveys demonstrate that almost $92 \%$ of recruitment professionals use social media sites such as LinkedIn and Facebook to evaluate candidates (Jobvite, 2015). These platforms strongly encourage "profile pictures", often providing the recruiter a face by which to process the candidate's resume.

The halo effect has been empirically demonstrated through the recruitment process on numerous occasions (Ndobo, 2014; Hosoda, Stone-Romero, \& Coats, 2003). This research often makes use of the "resume evaluation technique", in which participants evaluate applicants based on their resume and headshot. This methodology has revealed that both recruitment personnel and student populations allocate higher competences to attractive female applicants (Johnson, Podratz, Dipboye, \& Gibbons, 2010; Jawahar \& Mattsson, 2005). These findings are true for both trainee roles and managerial positions (Jackson Hunter \& Hodge, 1995), and particularly in sales occupations (Ndobo, 2014; Tsai, Huang, \& Yu, 2010).

In addition, observational studies reveal that regardless of qualification attractive men and women are more likely to receive call-backs from recruitment agencies (Busetta et al., 2013). Taken together, research demonstrates that more attractive females are more likely to be invited for interviews (Baert \& Decuypere, 2014), receive higher performance ratings (Drogosz \& Levy, 1996; Vilela, González, Ferrín, \& Araújo, 2007), more positive interview ratings (Barrick, Shaffer, \& Degrassi, 2009), higher earning potential (Musumeci \& Shahani-Denning, 1996), more managerial ability (Dean, 2014), as well as receive an increased chance of employment (Watkins \& Johnston, 2000).

Although the halo effect has proven robust through recent literature, research prior to the twenty first century often proposed a "beauty is beastly" effect 
(Heilman \& Saruwatari, 1979). This effect suggests that attractiveness can be detrimental for females within certain professions. These detrimental effects were specific to male dominated roles (i.e. automobile salesperson) and nonmanagerial positions (Cash et al., Gillen, \& Burns, 1977; Heilman \& Saruwatari, 1979). Heilman (1983) interpreted these findings through her lack of fit model. In previous decades women had lesser opportunity to work in managerial and male-dominated positions (Clegg, 2016). Masculine qualities were given higher value as they aligned with the expectations and stereotypes of society. Hence, when pursuing these positions more attractive women were judged harshly as their enhanced "feminine" qualities (Heilman \& Stopeck, 1985) failed to fit these expectations.

\subsection{The Role of Facial Cosmetics in Selection}

Research in this area often fails to consider the extended phenotype of beauty: the use of facial cosmetics. These cosmetics are highly prevalent throughout the workplace, as $64 \%$ of surveyed females claimed to "always" wear makeup in to work, and nearly all of these women (98\%) would wear makeup when attending a job interview (Leslie, 2013). Numerous studies demonstrate that perception of attractiveness can be directly enhanced through the application of facial cosmetics (Cash, Dawson, Davis, Bowen, \& Galumbeck, 1989; Mulhern, Fieldman, Hussey, Leveque, \& Pineau, 2003), particularly for less attractive women, as rated by observers (Jones \& Kramer, 2016). Following this line of logic, the current research aims to explore whether the use of facial cosmetics can interact with attractiveness to influence how women are perceived throughout the recruitment process.

The existing literature demonstrates a significant effect of facial cosmetics on professional evaluations of women (Kyle \& Mahler, 1996; Nash et al., 2006). Graham and Jouhar (1981) presented the earliest finding of an advantageous facial cosmetics bias in an organizational setting. Participants evaluated women wearing facial cosmetics to be more sociable, interesting, confident, poised, organized and popular. Mack and Rainey (1990) extended these positive effects of grooming (clothing, hair and facial cosmetics) to a recruitment setting. Wellgroomed applicants (wearing facial cosmetics) were deemed more hireable.

Nash et al., (2006) found that both male and female participants judged women to be healthier and more confident when wearing facial cosmetics, and have more prestigious jobs with a greater earning potential. The use of facial cosmetics has also been shown to dramatically increase appraisals for high social and professional status applicants as compared to low status applicants. These findings suggest that the effect of facial cosmetics may be stronger within women of high professional social status.

However, it has also been suggested that female applicants wearing facial cosmetics are judged more harshly for both female-typed secretarial positions (Cox \& Glick, 1986) and non-gender typed account positions (Kyle \& Mahler, 1996). Kyle and Mahler (1996) revealed that the negative bias towards applicants 
with facial cosmetics only presented itself within low status roles, for both female and male gender-typed roles. These findings support the notion that the use of facial cosmetics is related to social professional status as opposed to gender-typing of professions (Chao \& Schor, 1998).

Etcoff et al. (2011) found facial cosmetics had a significantly positive effect on likeability, competence and trustworthiness within automatic judgements. However, when participants were allocated enough time to make deliberate judgements, facial cosmetics produced more complex consequences for women. Natural and professional makeup looks had significant positive effects on likability while glamorous makeup look did not.

Firstly, throughout the literature "makeup" and "attractiveness" are often considered to have separate and direct effects on impression formation (Huguet, Croizet, \& Richetin, 2004). Attractiveness is often controlled or simply ignored (Nash et al, 2006; Cox \& Glick, 1986). In doing so, interaction or additive effects between these attributes have been neglected.

Secondly, previous studies applied cosmetics to facial stimuli using professional beauticians (Etcoff et al., 2011; Nash et al., 2006). Such procedures have been found to cause enhanced feelings of attractiveness and confidence (Cash, Dawson, Davis, Bowen, \& Galumbeck, 1989). To eliminate such demeanour effects, the current methods applied cosmetics to the stimuli faces using online makeover software, ensuring control over facial expression.

The current research aimed to uncover how facial cosmetics influence perceptions of professional women, both independently and in interaction with her perceived attractiveness and social professional status. In doing so, the current study made the following hypotheses:

1) The use of facial cosmetics will increase ratings of capability, earning potential, popularity, and hire-ability for female applicants (Etcoff et al., 2011).

2) Perception of attractiveness will increase ratings of capability, earning potential, popularity, and hire-ability for female applicants (Ndobo, 2014).

3) The use of facial cosmetics will increase ratings of capability, earning potential, popularity and hire-ability for unattractive female applicants more so than attractive female applications (Jones \& Kramer, 2016).

4) The use of facial cosmetics will increase capability, earning potential, popularity, and hire-ability for female applicants of a high social professional status role more so than females of a low professional status role (Nash et al., 2006).

\subsection{Pre-Study}

A pre-study was conducted to identify two "attractive" faces and two "less attractive" faces appropriate for the resume evaluation procedure. Participants were asked to rate 10 female faces (Ma et al., 2015) according to their attractiveness, health, happiness and trustworthiness using 7-point Likert scales (randomized). Using paired sample t-tests, the experimenters identified the two faces ranked as the most attractive $(\mathrm{M}=5.47, \mathrm{SD}=0.16)$ and two face that were 
ranked as the least attractive, $(\mathrm{M}=2.88, \mathrm{SD}=0.06), \mathrm{t}(2)=-16.2, p=0.04$. Moreover, these four faces showed no significant variation in perception of health scores, $\mathrm{t}(2)=-1.4, p=0.39$; happiness scores $\mathrm{t}(2)=-6.89, p=0.09$; perceived trust scores, $\mathrm{t}(2)=1, p=0.5$; or perceived age scores $\mathrm{t}(2)=2.57, p=0.24$. Data from the two stimuli faces within each attractiveness condition were collated for the main analysis, for both conditions the two faces showed no significant variation from one another under each dependant measure (See Appendix 1 and Appendix 2).

\section{Method}

\subsection{Participants}

In total, 289 participants ( 83 male, 208 females) took part in the study. The mean age of participants was 23 yrs $(S D=9.16)$, ranging from 18 - 60 years of age. All participants were fluent English speakers, and were mainly Caucasian (60\%). The second biggest ethnic population was Asian (30\%), while the remaining $10 \%$ consisted of Caribbean, Black, Hispanic and mixed ethnicities. 34\% of the participants identified themselves as having zero years of work experience, $41 \%$ between 1 to 3 years of employment experience, 9\% between $4-6$ years, and the remaining $16 \%$ of participants had $7+$ years of employment experience. Additionally, 61 participants (22\%) had significant experience with recruitment procedures.

\subsection{Materials}

\section{Images}

Stimuli images were obtained from the Chicago Face Base (Ma, Correll, \& Wittenbrink, 2015). Ten headshots from the neutral expression group were chosen. Five of these headshots represented the unattractive condition and the other five represented attractive condition, as determined by subjective norming data (Ma et al., 2015). All ten of the chosen headshots showed no statistically significant variation in judgements of age, emotional expressiveness, femininity, masculinity and trustworthiness as determined by subjective norming data and objective physical measurement data collected by the database authors (Ma et al., 2015). The current study ran an additional pre-test to identify four headshots for the experimental task. Two faces were chosen to represent each attractiveness group in order to ensure generalizability. Pre-study participants $(\mathrm{N}=12)$ were presented with each of the ten faces individually (randomized), and asked to rate the female's attractiveness, health, happiness, and trustworthiness. Analysis of these responses identified two faces to represent each attractiveness level that showed no statistical variation in ratings of health, happiness, trustworthiness and age.

Each of the four stimuli faces was photographed under uniform conditions, with no use of facial cosmetics and identical attire (Ma et al, 2015). The present experiment employed “ModiFace Makeover Software” (Version 1.2; Arabi, 2016) 
to form the professional makeup condition, in which products with identical intensities were applied (See Appendix 1). As within previous studies, facial cosmetics we're applied in a moderate quantity (Nash et al., 2006). Two versions of each face were created, one that received cosmetic modification and one that did not. This resulted in a total of 8 images all of which were given identical hairstyles with use of the "ModiFace Makeover Software" (See Appendix 3).

Resumes

Each stimuli image was attached to a resume both a sales assistant (low professional status) and sales manager (high professional status) position. The current study chose a sales position, as an appearance is valued for roles (Hosoda et al., 2003; McElroy \& DeCarol, 1999). All resumes contained a large image of the applicant $(3.91 " \times 2.75$ ") in the upper left hand corner. Information regarding the applicant's skills, education, languages spoken, contact details as well as work experience was provided. This information was kept consistent, apart from key terms (manager/assistant), education level (high school/university diploma) and expected starting salary ( $£ 25 / \$ 31,000$ vs. $£ 55 / \$ 68,000)$ dependent upon professional status condition. A total of 16 resumes were created for the experimental procedure, one of which randomly allocated to each participant. These resume designs mirrored those of past research (Desrumaux, Bosscher, \& Léoni, 2009; Nash et al., 2006) to provide comparison. An example is shown in Appendix 4.

\subsection{Procedure}

The experiment was performed on Qualtrics Software. Participants were recruited through the university departmental subject panel: hence the number of females. Ethics department approval was sought and obtained.

All participants were told to simulate the position of a "recruitment consultant", whose job is to evaluate and hire candidates for positions within organizations. Afterwards, participants were provided with a description and a list of desired characteristics for the role they were to recruit for, either a "sales manager" or "sales assistant" dependent upon their randomly assigned professional status condition. After evaluating the resume, participants were asked to individually rate the applicant on capability, earning potential, hire-ability and popularity for the role (counterbalanced) using four 7-point Likert scale's similar to those of past research. Participants were then asked to evaluate how the applicant attributes (appearance, work experience, education, and skills (counterbalanced) influenced their decision making processes, using a 7 Point Likert Scale. Thereafter, participants rated their personal attitudes towards facial cosmetics, jewellery and religious symbols in the workplace (measured on a 7-point Likert scale).

\section{Results}

\section{Dependent Measures}

The current experiment used 7-point Likert scales to measure ratings of capability, earning potential, popularity, and hire ability. A $2 \times 2 \times 2$ (Perceived Attrac- 
tiveness [low, high] $\times$ Professional Status [low, high] $\times$ Facial Cosmetics [Present/Absent]) between prticipants analysis of variance (ANOVA) was conducted. All results are shown in Table 1.

Figure 1 and Figure 2 show clearly the pattern of results.

1) Capability

There was a significant main effect of cosmetic usage on capability ratings, $\mathrm{F}(1,281)=5.92, p=0.02, \eta^{2}=1.6 \%$, indicating a significant increase in capability ratings for female applicants wearing professional facial cosmetics $(\mathrm{M}=4.79, \mathrm{SD}$ $=0.08)$ as compared to applicants wearing no cosmetics $(\mathrm{M}=4.50, \mathrm{SD}=0.08)$.

There was a significant main effect of attractiveness on capability ratings $\mathrm{F}(1$, $281)=22.6, p<0.001, \eta^{2}=7.5$. Capability ratings were higher in attractive applicants $(\mathrm{M}=4.92, \mathrm{SD}=0.08)$ than unattractive applicants $(\mathrm{M}=4.36, \mathrm{SD}=$ 0.08). Analysis of variance methods revealed a significant main effect of professional status on capability scores, $\mathrm{F}(1,281)=8.27, p=0.004, \eta^{2}=2.9 \%$. Low professional status applicants were judged more capable $(\mathrm{M}=4.8, \mathrm{SD}=0.08)$ than high status applicants $(\mathrm{M}=4.5, \mathrm{SD}=0.08)$.

Analysis of variance revealed a significant interaction between facial cosmetics and attractiveness, $\mathrm{F}=33.47, p<0.001, \eta^{2}=10.6$. Further simple effects analysis demonstrated that the effect of facial cosmetics was significant for both attractive and unattractive applicants, however in different directions. Unattractive applicants received higher ratings of capability when wearing facial cosmetics $(\mathrm{M}=$ $4.85, \mathrm{SD}=0.12)$ than without $(\mathrm{M}=3.88, \mathrm{SD}=0.12), \mathrm{F}(1,143)=32.97, p<0.001$, $\eta^{2}=18.7$. While attractive applicants received higher ratings of capability without facial cosmetics $(\mathrm{M}=5.11, \mathrm{SD}=0.18)$ than with $(\mathrm{M}=4.73, \mathrm{SD}=0.12)$, $\mathrm{F}(1,142)=5.35, p=0.02, \eta^{2}=3.7$.

Additionally, an interaction reaching partial significance between attractiveness and professional status was discovered, $\mathrm{F}(1,281)=3.35, p=0.06, \eta^{2}=1.2$. Simple effects revealed that for high professional status positions, attractive applicants were judged as more capable $(\mathrm{M}=4.86, \mathrm{SD}=0.12)$ than unattractive applicants $(\mathrm{M}=4.09, \mathrm{SD}=0.12), \mathrm{F}(1,144)=19.5, p<0.001, \eta^{2}=12$. While for

Table 1. Ratings of capability.

\begin{tabular}{|c|c|c|c|c|c|c|c|c|c|c|}
\hline \multicolumn{3}{|c|}{ Ratings for Female Applicants } & \multicolumn{2}{|c|}{ Average Capability } & \multicolumn{2}{|c|}{ Average Popularity } & \multicolumn{2}{|c|}{$\begin{array}{l}\text { Average Earning } \\
\text { Potential }\end{array}$} & \multicolumn{2}{|c|}{$\begin{array}{c}\text { Average } \\
\text { Hire-Ability }\end{array}$} \\
\hline Attractiveness & Status & Makeup & Mean & SD & Mean & SD & Mean & SD & Mean & SD \\
\hline \multirow{4}{*}{ Less attractive } & \multirow{2}{*}{ Low } & No Makeup & 4.20 & 1.12 & 4.60 & 0.88 & 3.11 & 1.27 & 3.74 & 1.29 \\
\hline & & Professional Makeup & 5.08 & 0.83 & 4.46 & 1.09 & 3.19 & 1.13 & 4.27 & 1.37 \\
\hline & \multirow{2}{*}{ High } & No Makeup & 3.57 & 0.98 & 3.84 & 0.96 & 2.27 & 1.19 & 3.30 & 1.10 \\
\hline & & Professional Makeup & 4.65 & 0.99 & 4.61 & 0.96 & 2.75 & 1.05 & 3.81 & 1.23 \\
\hline \multirow{4}{*}{ Attractive } & \multirow{2}{*}{ Low } & No Makeup & 5.26 & 0.89 & 4.74 & 0.93 & 3.41 & 1.05 & 4.24 & 1.13 \\
\hline & & Professional Makeup & 4.61 & 1.05 & 5.16 & 1.19 & 3.49 & 1.17 & 4.30 & 1.15 \\
\hline & \multirow{2}{*}{ High } & No Makeup & 4.97 & 0.95 & 4.68 & 0.92 & 2.97 & 1.78 & 4.08 & 1.23 \\
\hline & & Professional Makeup & 4.75 & 1.07 & 4.78 & 1.04 & 2.86 & 1.33 & 4.17 & 1.44 \\
\hline
\end{tabular}

Note: Higher scores indicate more positive perception of hire-ability (i.e. $6=$ likely to hire). 


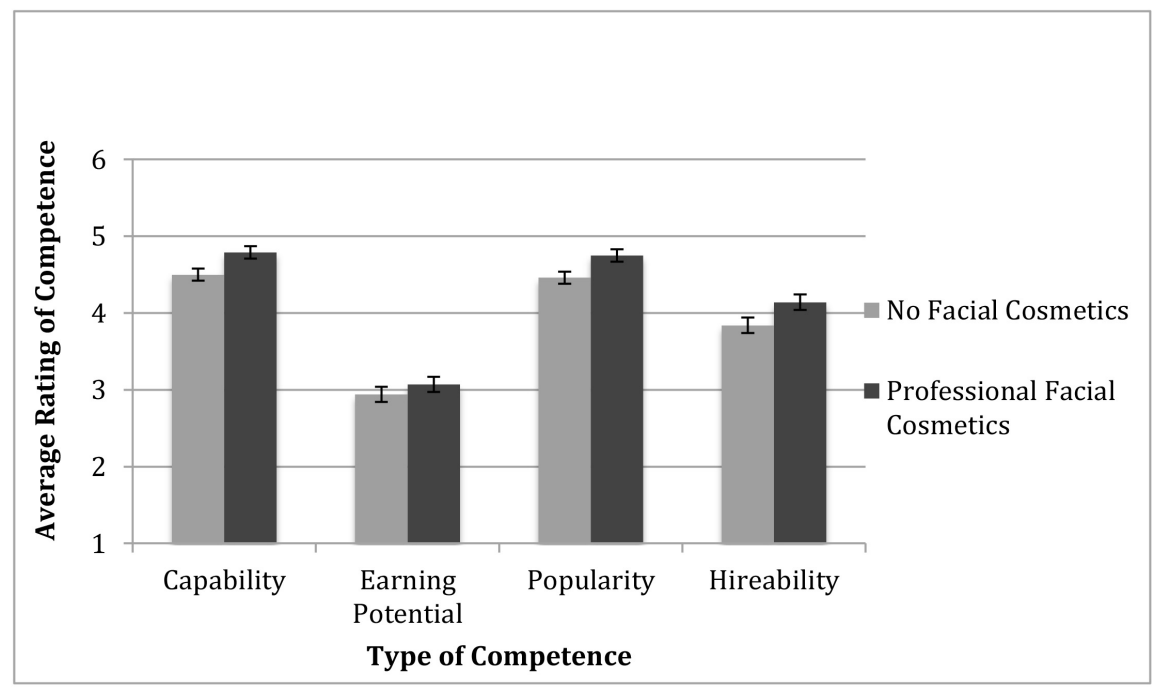

Figure 1. The effect of facial cosmetics on ratings of applicant competence.

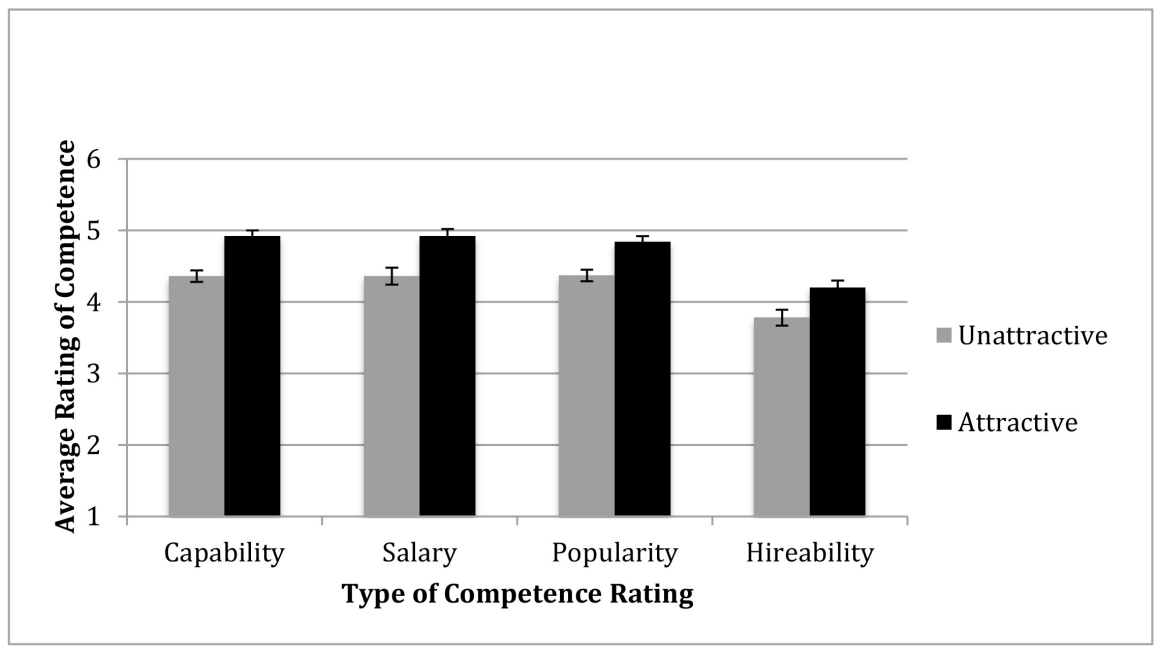

Figure 2. The effect of perceived attractiveness on average ratings of applicant competence.

low status positions there was no significant difference between attractive applicants $(\mathrm{M}=4.98, \mathrm{SD}=0.012)$ and unattractive applicants $(\mathrm{M}=4.65, \mathrm{SD}=0.12)$, $\mathrm{F}(1,141)=3.33, p=0.07, \eta^{2}=2.3$. Finally, there was no significant interaction between professional status and facial cosmetics for measures of capability.

2) Earning Potential

A second three-way between subjects analysis variance showed no significant main effect of facial cosmetics on judgements of earning potential, $\mathrm{F}(1,287)=$ $0.74, p=0.39, \eta^{2}=0.37$ However, judgements of earning potential were significantly higher in in attractive applicants $(\mathrm{M}=3.18, \mathrm{SD}=1.3)$ than unattractive applicants $(\mathrm{M}=2.83, \mathrm{SD}=1.2), \mathrm{F}(1,287)=5.49, p=0.02, \eta^{2}=1.8$. Analysis also revealed a significant main effect of status, $\mathrm{F}(1,287)=15.25, p<0.001, \eta^{2}=5.1$. Ratings of earning potential were significantly higher in low status applicants ( $M$ $=3.30, \mathrm{SD}=0.12)$ than high status applicants $(\mathrm{M}=2.71, \mathrm{SD}=0.12)$. Finally, at- 
tractiveness, facial cosmetics and professional status showed no interaction in earning potential ratings.

3) Popularity

A third three-way between subjects analysis of variance revealed a significant main effect of facial cosmetics on popularity judgements, $\mathrm{F}(1,281)=6.05, p=$ $0.02, \eta^{2}=2.1$. Popularity scores were significantly higher in female applicants with facial cosmetics $(\mathrm{M}=4.75, \mathrm{SD}=0.08)$ than applicants with no cosmetics $(\mathrm{M}=4.46, \mathrm{SD}=0.08)$. There was also a significant main effect of attractiveness on popularity scores $\mathrm{F}(1,281)=15.2, p<0.001, \eta^{2}=5.1$, popularity ratings were significantly higher in attractive applicants $(\mathrm{M}=4.84, \mathrm{SD}=0.08)$ than unattractive applicants $(M=4.37, S D=0.08)$. Lastly, there was a significant main effect of professional status on popularity judgements, $\mathrm{F}(1,281)=4.97, p=0.03, \eta^{2}=$ 1.7 , as low status applicants were judged as more popular $(\mathrm{M}=4.74, \mathrm{SD}=0.09)$ when compared to high status applicants $(\mathrm{M}=4.47, \mathrm{SD}=0.08)$.

There was no significant interaction between attractiveness and status or attractiveness and facial cosmetics for popularity ratings. However, as revealed by a significant three way interaction, professional status and facial cosmetics showed interaction for unattractive applicants, $\mathrm{F}(1,281)=6.86, p=0.01, \eta^{2}=$ 2.4. Simple effects analysis demonstrated that in unattractive groups, high status applicants were perceived as more popular with facial cosmetics $(\mathrm{M}=4.61, \mathrm{SD}=$ $0.17)$ than without $(\mathrm{M}=3.84, \mathrm{SD}=0.16), \mathrm{F}(1,72)=11.8, p=0.01, \eta^{2}=1.4$. However for low status applicants, females wearing cosmetics did not receive enhanced popularity scores $(\mathrm{M}=4.5, \mathrm{SD}=0.16)$ when compared to females wearing no facial cosmetics $(\mathrm{M}=4.6, \mathrm{SD}=0.16), \mathrm{F}(1,70)=0.36, p=0.55, \eta^{2}=$ $0.5 \%$. No such interaction presented itself for popularity judgements within attractive applicants, $\mathrm{F}(1,140)=0.89, p=0.35, \eta^{2}=0.6$.

4) Hire-ability

A fourth three-way between subjects analysis of variance revealed a significant main effect of facial cosmetics on hire-ability ratings, $\mathrm{F}(1,281)=4.01 p=0.05$, $\eta^{2}=1.4$. Hence participants were more likely to hire applicant's wearing facial cosmetics $(\mathrm{M}=4.14, \mathrm{SD}=0.1)$ as compared to applicants wearing no cosmetics $(\mathrm{M}=3.84, \mathrm{SD}=0.1)$. Secondly, there was a significant main effect of applicant attractiveness on hire-ability ratings $\mathrm{F}(1,281)=7.92, p=0.01, \eta^{2}=2.7$. Hire decision ratings were significantly higher in attractive applicants $(\mathrm{M}=4.19, \mathrm{SD}=$ $0.1)$ than unattractive $(\mathrm{M}=3.78, \mathrm{SD}=0.1)$. Lastly, high status applicants received significantly lower hire-ability ratings $(\mathrm{M}=3.84, \mathrm{SD}=0.1)$ than low professional status applicants $(\mathrm{M}=4.14, \mathrm{SD}=0.1), \mathrm{F}(1,281)=4.08, p=0.04, \eta^{2}=$ 2.7.

No significant interaction was found between facial cosmetics and professional status, facial cosmetics and attractiveness, as well as attractiveness and status for hire-ability judgements. However, further simple effects analysis revealed a trend between cosmetics usage and attractiveness, similar to the interaction discovered within capability measures. The use of cosmetics significantly 
improved hire-ability ratings for unattractive applicants, $\mathrm{F}(1,143)=6.2, p=0.02$, $\eta^{2}=4.1$, (Professional Makeup: $M=4.1$ VS. No Makeup: $M=3.5$ ). While in attractive applicants, there was no significant difference between cosmetics conditions $\mathrm{F}(1,142)=0.14, p=0.71, \eta^{2}=1$, (Professional Makeup: $\mathrm{M}=4.23$, No Makeup: $M=4.15)$. Descriptive Statistics for hire-ability ratings are presented between conditions are presented within Table 1.

\section{Discussion}

In the current study it was hypothesized that higher levels of attractiveness and professional use of facial cosmetics would increase ratings of capability, earning potential, popularity, and hire-ability for female applicants under a resume evaluation procedure. Secondly, facial cosmetics would be more advantageous for less attractive applicants and managerial applicants. The first three hypotheses were fully supported, while the final hypothesis received partial support through statistical analysis. The current findings conclude that perceptions of women in recruitment procedures are significantly increased by use of facial cosmetics. However, contrary to previous findings, the extent of this facial cosmetics bias depends upon level of perceived attractiveness and professional status.

\subsection{The Facial Cosmetics Bias}

The current findings demonstrate that the overall use of facial cosmetics enhanced judgements of capability, popularity and hire-ability for female applicants. These conclusions fall in line with recent findings (Etcoff et al., 2011; Nash et al., 2006), while opposing the conclusions of more dated research (Cox \& Glick, 1986; Kyle \& Mahler, 1996).

These discrepancies can be explained through implicit personality theory (Ashmore \& Del Boca, 1979). In the past, cosmetics held negative effects for professional women as feminine qualities deviated from society's expectations of a male-dominated workplace. However facial cosmetics are often used on a day-to-day basis (Britton, 2012). It is not surprising that these changes in our society have altered expectations held towards women for organizational practices. As facial cosmetics have become commonplace, they no longer carry detrimental consequences for women within organizational procedures.

According to a recent survey, almost two thirds of women claim to "always" wear makeup to work, and nearly all of these women would wear makeup when being interviewed for a job (Leslie, 2013). As wearing facial cosmetics has become a common social convention, society now holds expectations for women to use these makeup products in their place of work. Almost half of surveyed employers stated that makeup would factor into hiring decisions for a public-facing role, and two thirds said they would take a dim view of female staff if they attended important meetings without the use of cosmetics (Leslie, 2013). It appears that facial cosmetics have become a crucial symbol of effort for women 
in the workplace. Therefore, when women fail to reflect this effort, negative impressions arise.

\subsection{The Halo Effect}

In support of the second hypothesis, attractive female applicants were rated favourably on measures of capability, earning potential, popularity and hire-ability when compared to unattractive applicants. This finding supports the well-demonstrated halo effect in the process of organizational recruitment (Ndobo, 2014, Jackson et al., 1995). As the workforce has become increasingly gender-balanced, enhancing femininity through attractiveness no longer holds detrimental consequences for women. Instead, attractiveness enhances perceptions of valued feminine qualities such as altruism and expressiveness (Desrumaux, Bosscher, \& Léoni, 2009).

\subsection{Facial Cosmetics and Attractiveness}

In support of the third hypothesis, the use of facial cosmetics increased ratings of capability for unattractive female applicants more so than attractive female applications. Facial cosmetics lead to significantly enhanced perceptions of capability for less attractive applicants. Whilst unexpectedly, facial cosmetics lead to a more subtle diminished perception of capability for attractive applicants. These findings challenge the conclusions of previous research in a number of ways. Firstly, we must reject the assumption that attractiveness and facial cosmetics influence social perception independently (Etcoff et al., 2011; Graham \& Jouhar, 1981; Nash et al., 2006). The current findings suggest that a complex interplay between these perceptual factors exists. As such, facial cosmetics and perceived attractiveness simultaneously influence decision-making processes in recruitment procedures.

The current findings established that facial cosmetics did not cause a universally advantageous effect for professional females, unlike previously proposed (Nash et al., 2006). In fact, facial cosmetics led to detrimental effects for women with high levels of underlying physical attractiveness. This effect was significant within measures of capability, with a similar (yet insignificant) pattern emerging for hire-ability. However, this negative effect is more subtle than the advantageous effect of facial cosmetics for unattractive female applicants.

This finding may be interpreted in a number of ways. Firstly, it is possible that when attractive women use facial cosmetics, they appear to place excessive effort towards their physical appearance as opposed to their professional capabilities. This leads impressions of vanity, consistent with the "what is beautiful is self-centred" effect (Cash \& Janda, 1984). Secondly, high levels of beauty (from both attractiveness and facial cosmetics) may cause women to be perceived in sexualized manor. These impressions contradict the expectations held for women in organizational settings, resulting in negative impressions. Finally, it is possible that this interaction may explain the previously demonstrated negative 
effect of facial cosmetics. Therefore, stimuli may have been negatively viewed due to the combination of attractiveness and facial cosmetics, as opposed to just the use of facial cosmetics. Nonetheless, it appears that attractive women need not rely on beauty-enhancement tools, unlike their unattractive counterparts.

\subsection{Facial Cosmetics and Professional Status}

The fourth hypothesis was partially supported through statistical analysis. The use of facial cosmetics increased popularity judgements for female applicants of a high status role more so than for a low status role, but only within groups of less attractive applicants. This interaction proved nonsignificant for attractive stimuli, therefore the hypothesis cannot be fully accepted. Nonetheless, less attractive high status applicants were deemed more popular with use of facial cosmetics, while less attractive low status applicants showed no increase in popularity judgements through the use of cosmetics.

These findings infer that facial cosmetics carry more influence within managerial positions. When women fail to meet these expectations their professional image may be compromised. Yet, why was this interaction limited to less attractive applicants? Possibly attractive women may already meet the standard of beauty expected within managerial positions, while less attractive applicants must employ beauty enhancement tools such as facial cosmetics to rise to these standards. As this interaction was present within popularity measures these expectations appear to be specific to social competences.

\subsection{Attractiveness and Professional Status}

The analysis revealed that high status applicants were deemed more capable when attractive, while low status applicants showed no enhanced capability judgements as a result of attractiveness. It appears that more value is placed on physical attractiveness within managerial positions when compared to assistant positions. These findings confirm past demonstrations of enhanced halo effects for women seeking managerial positions (Desrumauxl, Bosscher, \& Léoni, 2009). As this result shows similarity to the previous findings, it appears that individuals carry higher expectations for both genotypic and phenotypic beauty in managerial positions.

There are practical implications of this research. The first should be for recruiters not to misinterpret physical attractiveness presuming it is related to a range of other characteristics. The second is to examine their personal theories of make-up use to examine the possibility of any bias.

\section{Limitations}

Firstly, the facial cosmetics were applied to the model stimuli using an online makeup application software. This method of application may not mirror the natural application of facial cosmetics by professional women, limiting the ecological validity of the findings. Indeed, we did not distinguish between different 
styles or amounts of make-up. Research has shown that attractiveness is further enhanced when cosmetics are applied by a professional then by women themselves (Jones \& Kramer, 2016).

Secondly, the use of facial stimuli fails to account for perceptual attributes outside of the face. For example, attire has shown to guide professional perceptions of women. Female managers are viewed as less capable with subtly provocative attire, and lawyers less capable when dressed in casual or smart attire (Furnham, Chan, \& Wilson, 2013).

Thirdly, recruitment personal are likely to review several resumes for a single role in a limited time frame. As the current procedures merely asked participants to review one applicant (to eliminate detection effects) they may not accurately reflect how perceptual bias carries across the entire recruitment procedure. It would be valuable for future research to evaluate how facial cosmetics influence perceptions of females under processes of candidate comparison.

Fourth, the current experiment only measured the influence of facial cosmetics and the halo effect on Caucasian females, similar to previous research in this field. Moreover, the participants tested were largely of Caucasian ethnicity. As such, it is possible racial in-group biases may have taken place. Further research is necessary to understand how the facial cosmetics bias may function across cultures, and generalize the current conclusions beyond a Caucasian demographic.

Fifth, we were limited by our sample of young people and the particular job we chose. It may be that older people with more experience of cosmetics may have very different opinions. Further, the particular job chosen in this study, namely the sales role, may have made people particularly sensitive to cosmetics.

Finally, we held applicant qualifications constant between conditions, yet in may be argued that the requirements for a manager would higher than for a non-manager. Therefore, we could have manipulated applicant quality (qualified vs. underqualified) instead of low vs. high status. Some of the results (showing more negative perceptions of manager applicants) might be interpreted from this perspective. Thus, the manipulation of status appears to be confounded by at least two alternate variables, making the related analyses difficult to interpret. This could be investigated in future studies.

\section{Conclusion}

This study demonstrated, yet again, that physical characteristics have an impact on competence judgements in the workplace. Despite the fact that there is very little evidence that facial attractiveness and use of cosmetics are related to workplace competence and success this study has shown that these beliefs persist.

\section{Conflicts of Interest}

The authors declare no conflicts of interest regarding the publication of this paper. 


\section{References}

Arabi, P. Dr. (2016). ModiFace Virtual Makeover [Computer Software]. http://modiface.com/

Ashmore, R. D., \& Boca, F. K. (1979). Sex Stereotypes and Implicit Personality Theory: Toward a Cognitive-Social Psychological Conceptualization. Sex Roles, 5, 219-248. https://doi.org/10.1007/BF00287932

Baert, S., \& Decuypere, L. (2014). Better Sexy than Flexy? A Lab Experiment Assessing the Impact of Perceived Attractiveness and Personality Traits on Hiring Decisions. Applied Economics Letters, 21, 597-601. https://doi.org/10.1080/13504851.2013.877564

Barrick, M. R., Shaffer, J. A., \& Degrassi, S. W. (2009). What You See May Not Be What You Get: Relationships among Self-Presentation Tactics and Ratings of Interview and Job Performance. Journal of Applied Psychology, 94, 1394-1411. https://doi.org/10.1037/a0016532

Britton, A. M. (2012). The Beauty Industry's Influence on Women in Society. Honors Theses, Paper 86.

Busetta, G., Fiorillo, F., \& Visalli, E. (2013). Searching for a Job Is a Beauty Contest. $\mathrm{Mu}$ nich Personal RePEc Archice, Paper No. 49825, SSRN Electronic Journal. https://doi.org/10.2139/ssrn.2331921

Cash, T. F., Gillen, B., \& Burns, D. S. (1977). Sexism and Beautyism in Personnel Consultant Decision Making. Journal of Applied Psychology, 62, 301-310. https://doi.org/10.1037/0021-9010.62.3.301

Cash, T., Dawson, K., Davis, P., Bowen, M., \& Galumbeck, C. (1989). Effects of Cosmetics Use on the Physical Attractiveness and Body Image of American College Women. Journal of Social Psychology, 129, 349-355. https://doi.org/10.1080/00224545.1989.9712051

Cox, C. L., \& Glick, W. H. (1986). Resume Evaluations and Cosmetics Use: When More Is Not Better. Sex Roles, 14, 51-58. https://doi.org/10.1007/BF00287847

Davies, A. P., Goetz, A. T., \& Shackelford, T. K. (2008). Exploiting the Beauty in the Eye of the Beholder: The Use of Physical Attractiveness as a Persuasive Tactic. Personality and Individual Differences, 45, 302-306. https://doi.org/10.1016/j.paid.2008.04.016

Dean, D. H. (2014). A "Halo" Effect for Inference of Managerial Ability from Physical Appearance. American International Journal of Contemporary Research, 4.

Desrumaux, P., Bosscher, S. D., \& Léoni, V. (2009). Effects of Facial Attractiveness, Gender, and Competence of Applicants on Job Recruitment. Swiss Journal of Psychology, 68, 33-42. https://doi.org/10.1024/1421-0185.68.1.33

Dion, K., Berscheid, E., \& Walster, E. (1972). What Is Beautiful Is Good. Journal of Personality and Social Psychology, 24, 285-290. https://doi.org/10.1037/h0033731

Dipboye, R. L., Fromkin, H. L., \& Wiback, K. (1975). Relative Importance of Applicant Sex, Attractiveness, and Scholastic Standing in Evaluation of Job Applicant Resumes. Journal of Applied Psychology, 60, 39-43. https://doi.org/10.1037/h0076352

Drogosz, L. M., \& Levy, P. E. (1996). Another Look at the Effects of Appearance, Gender, and Job Type on Performance-Based Decisions. Psychology of Women Quarterly, 20, 437-445. https://doi.org/10.1111/j.1471-6402.1996.tb00310.x

Eagly, A. H., Ashmore, R. D., Makhijani, M. G., \& Longo, L. C. (1991). What Is Beautiful Is Good, but: A Meta-Analytic Review of Research on the Physical Attractiveness Stereotype. Psychological Bulletin, 110, 109-128.

Etcoff, N. L., Stock, S., Haley, L. E., Vickery, S. A., \& House, D. M. (2011). Cosmetics as a 
Feature of the Extended Human Phenotype: Modulation of the Perception of Biologically Important Facial Signals. PLoS ONE, 6, e25656.

https://doi.org/10.1371/journal.pone.0025656

Furnham, A., Chan, P. S., \& Wilson, E. (2013). What to Wear? The Influence of Attire on the Perceived Professionalism of Dentists and Lawyers. Journal of Applied Social Psychology, 43, 1838-1850.

Graham, J. A., \& Jouhar, A. J. (1981). The Effects of Cosmetics on Person Perception. International Journal of Cosmetic Science, 3, 199-210. https://doi.org/10.1111/j.1467-2494.1981.tb00283.x

Heilman, M. E. (1983). Sex Bias in Work Settings: The Lack of Fit Model. Research in Organizational Behavior, 5, 269-298

Heilman, M. E., \& Saruwatari, L. R. (1979). When Beauty Is Beastly: The Effects of Appearance and Sex on Evaluations of Job Applicants for Managerial and Nonmanagerial Jobs. Organizational Behavior and Human Performance, 23, 360-372. https://doi.org/10.1016/0030-5073(79)90003-5

Heilman, M. E., \& Stopeck, M. H. (1985). Attractiveness and Corporate Success: Different Causal Attributions for Males and Females. Journal of Applied Psychology, 70, 379-388. https://doi.org/10.1037/0021-9010.70.2.379

Hosoda, M., Stone-Romero, E. F., \& Coats, G. (2003). The Effects of Physical Attractiveness on Job-Related Outcomes: A Meta-Analysis of Experimental Studies. Personnel Psychology, 56, 431-462. https://doi.org/10.1111/j.1744-6570.2003.tb00157.x

Huguet, P., Richetin, J., \& Croizet, J. (2004). Facial Make-Up Elicits Positive Attitudes at the Implicit Level: Evidence from the Implicit Association Test. Current Research in Social Psychology, 9.

Jackson, L. A., Hunter, J. E., \& Hodge, C. N. (1995). Physical Attractiveness and Intellectual Competence: A Meta-Analytic Review. Social Psychology Quarterly, 58, 108. https://doi.org/10.2307/2787149

Jawahar, I. M., \& Mattsson, J. (2005). Sexism and Beautyism Effects in Selection as a Function of Self-Monitoring Level of Decision Maker. Journal of Applied Psychology, 90, 563-573. https://doi.org/10.1037/0021-9010.90.3.563

Jobvite (2015). Recruiter Nation Survey (1st ed., Vol. 1, pp. 1-21, Rep.).

Johnson, S. K., Podratz, K. E., Dipboye, R. L., \& Gibbons, E. (2010). Physical Attractiveness Biases in Ratings of Employment Suitability: Tracking Down the "Beauty Is Beastly" Effect. Journal of Social Psychology, 150, 301-318. https://doi.org/10.1080/00224540903365414

Jones, A. L., \& Kramer, R. S. (2016). Facial Cosmetics and Attractiveness: Comparing the Effect Sizes of Professionally-Applied Cosmetics and Identity. PLOS ONE, 11, e0164218. https://doi.org/10.1371/journal.pone.0164218

Kyle, D. J., \& Mahler, H. I. (1996). The Effects of Hair Color and Cosmetic Use on Perceptions of a Female's Ability. Psychology of Women Quarterly, 20, 447-455. https://doi.org/10.1111/j.1471-6402.1996.tb00311.x

Leslie, E. (2013). Survey of Makeup in the Workplace (Rep.). Escentual.com.

Lucker, G. W., Beane, W. E., \& Helmreich, R. L. (1981). The Strength of the Halo Effect in Physical Attractiveness Research. Journal of Psychology, 107, 69-75. https://doi.org/10.1080/00223980.1981.9915206

Ma, D. S., Correll, J., \& Wittenbrink, B. (2015). The Chicago Face Database: A Free Stimulus Set of Faces and Norming Data. Behavior Research Methods, 47, 1122-1135. https://doi.org/10.3758/s13428-014-0532-5 
Mack, D., \& Rainey, D. (1990). Female Applicants' Grooming and Personnel Selection. Journal of Social Behavior \&amp; Personality, 5, 339-407.

Mulhern, R., Fieldman, G., Hussey, T., Leveque, J., \& Pineau, P. (2003). Do Cosmetics Enhance Female Caucasian Facial Attractiveness? International Journal of Cosmetic Science, 25, 199-205.

Musumeci, C., \& Shahani-Denning, C. (1996). Self-Monitoring: Impact on Applicant Attractiveness and Selection Decisions. Paper Presented at the Annual Convention of the Society for Industrial and Organizational Psychology.

Nash, R., Fieldman, G., Hussey, T., Lévêque, J., \& Pineau, P. (2006). Cosmetics: They Influence More than Caucasian Female Facial Attractiveness. Journal of Applied Social Psychology, 36, 493-504. https://doi.org/10.1111/j.0021-9029.2006.00016.x

Ndobo, A. (2014). Attractiveness Effect and the Hidden Discourse of Discrimination in Recruitment: The Moderating Role of Job Types and Gender of Applicants. Presses Universitaires de Grenoble, 27, 127-144.

Tsai, W., Huang, T., \& Yu, H. (2010). Investigating the Unique Predictability and Boundary Conditions of Applicant Physical Attractiveness and Non-Verbal Behaviours on Interviewer Evaluations in Job Interviews. Journal of Occupational and Organizational Psychology, 85, 60-79. https://doi.org/10.1348/2044-8325.002003

Vilela, B. B., González, J. A., Ferrín, P. F., \& Araújo, M. L. (2007). Impression Management Tactics and Affective Context: Influence on Sales Performance Appraisal. European Journal of Marketing, 41, 624-639. https://doi.org/10.1108/03090560710737651

Watkins, L. M., \& Johnston, L. (2000). Screening Job Applicants: The Impact of Physical Attractiveness and Application Quality. International Journal of Selection and Assessment, 8, 76-84. https://doi.org/10.1111/1468-2389.00135 


\section{Appendix 1}
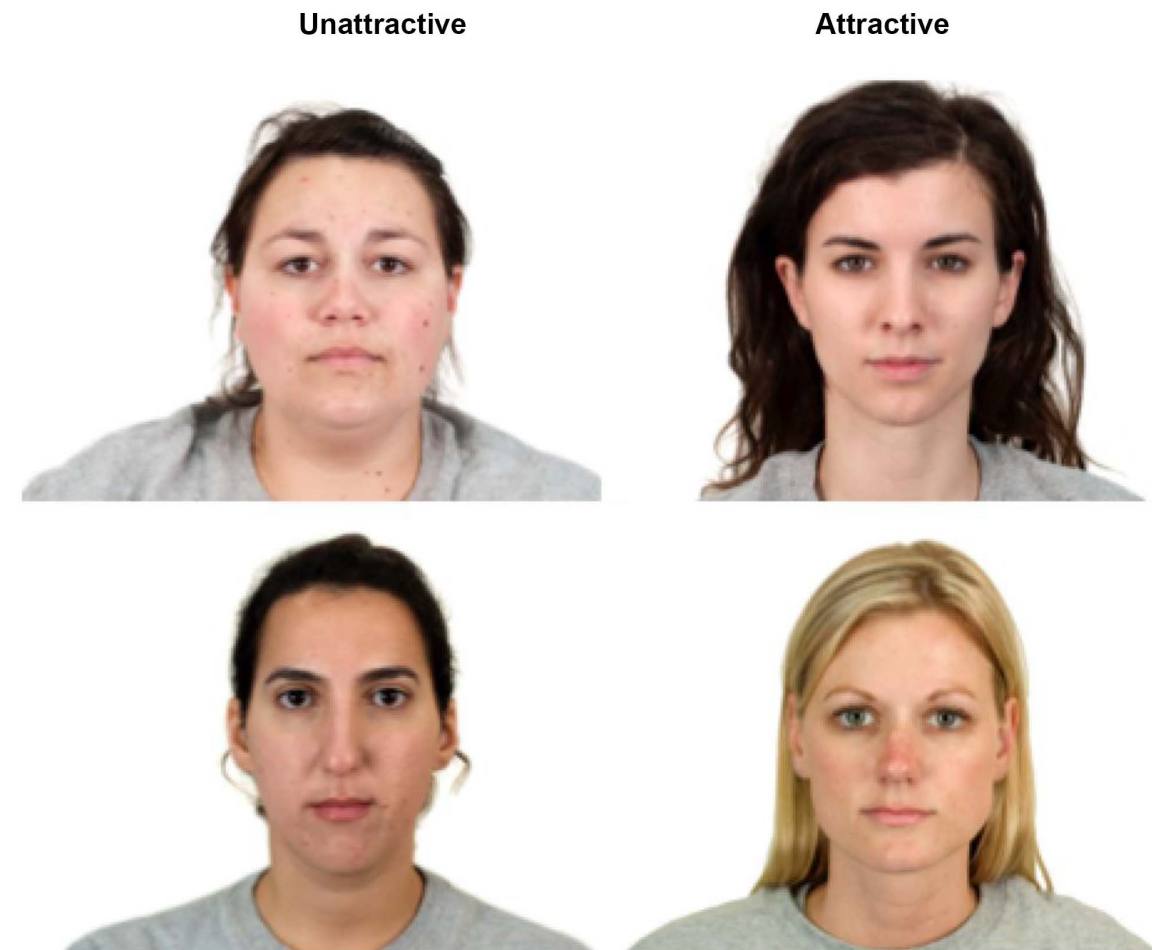

Figure A1. Original face stimuli.

\section{Appendix 2}

\section{Attractive Stimull Faces}

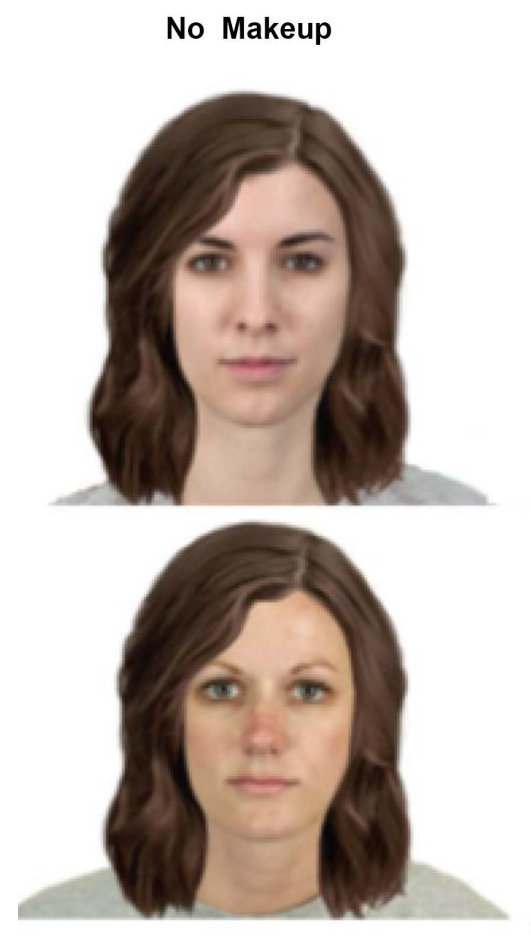

Professional Makeup

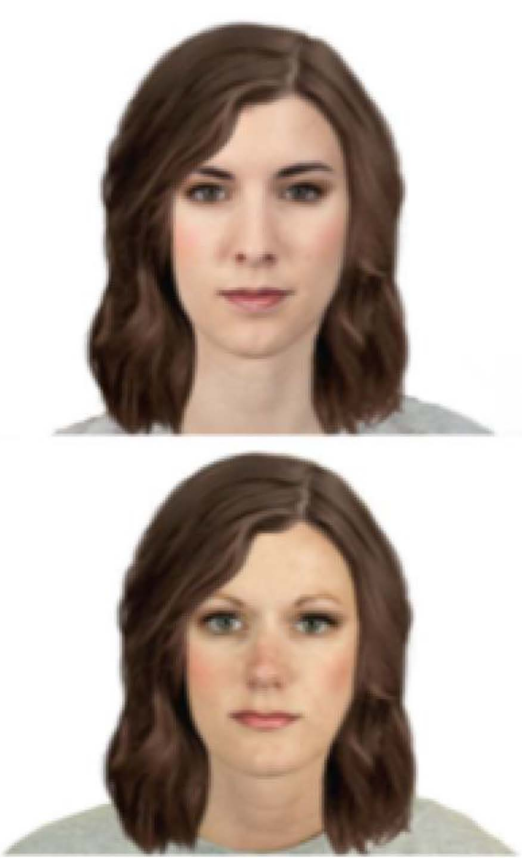

(a) 


\section{Attractive Stimull Faces}

No Makeup
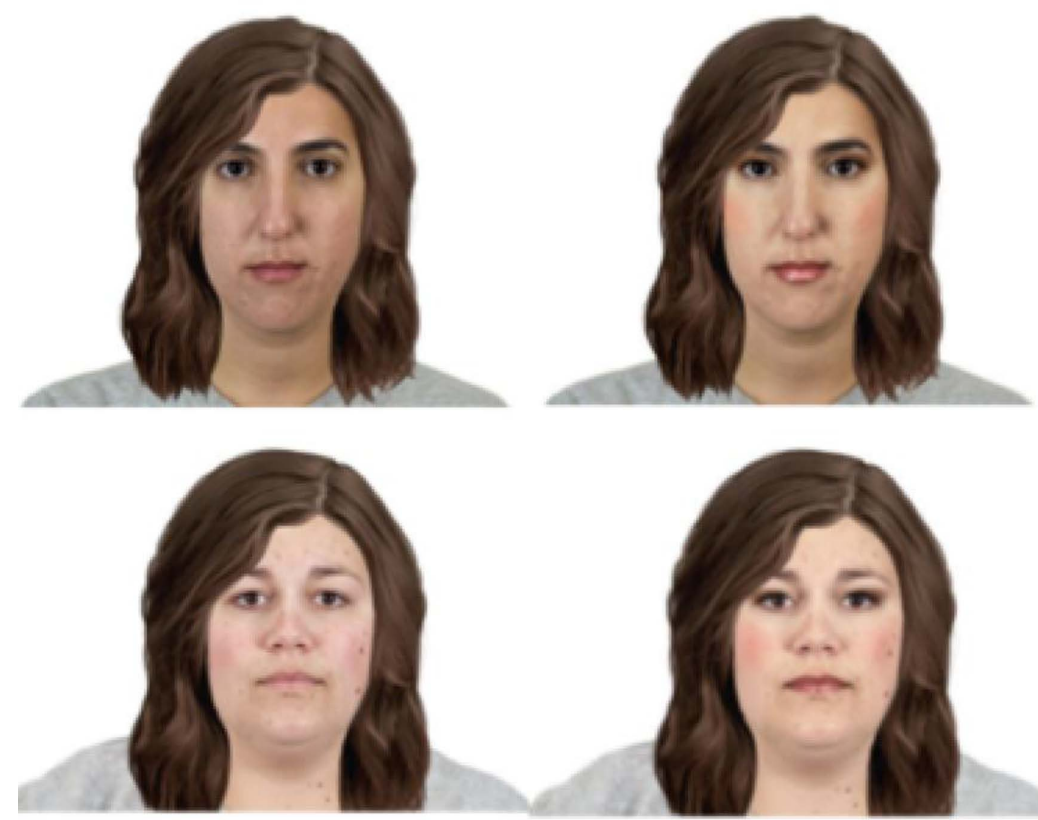

Professional Makeup

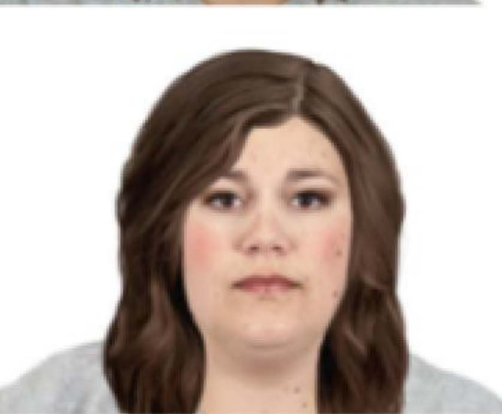

(b)

Figure A2. All stimuli images.

\section{Appendix 3: Cosmetics List}

No Facial Cosmetics Condition

Hair: Medium Clarion natural dark golden/brown cappuccino

Professional Facial Cosmetics Condition

Hair: Medium Clarion natural dark golden/brown cappuccino

Foundation: Stila illuminating 80 watts (75\%)

Concealer: Jane Ardele active light 1 (50\%)

Blush: INGLOT 70 (75\%)

Bronzer: INGLOT 74 (100\%)

Eyes: Jane Ardele Champagne Citrine (45\%)

Eye Liner: Makeup Forever Matt Black (50\%)

Mascara: Stila forever (75\%)

Brow Product: NYX Brunette (100\%)

Lipstick: Jane Just Kissed Plumper Sydney (75\%) 


\section{Appendix 4}

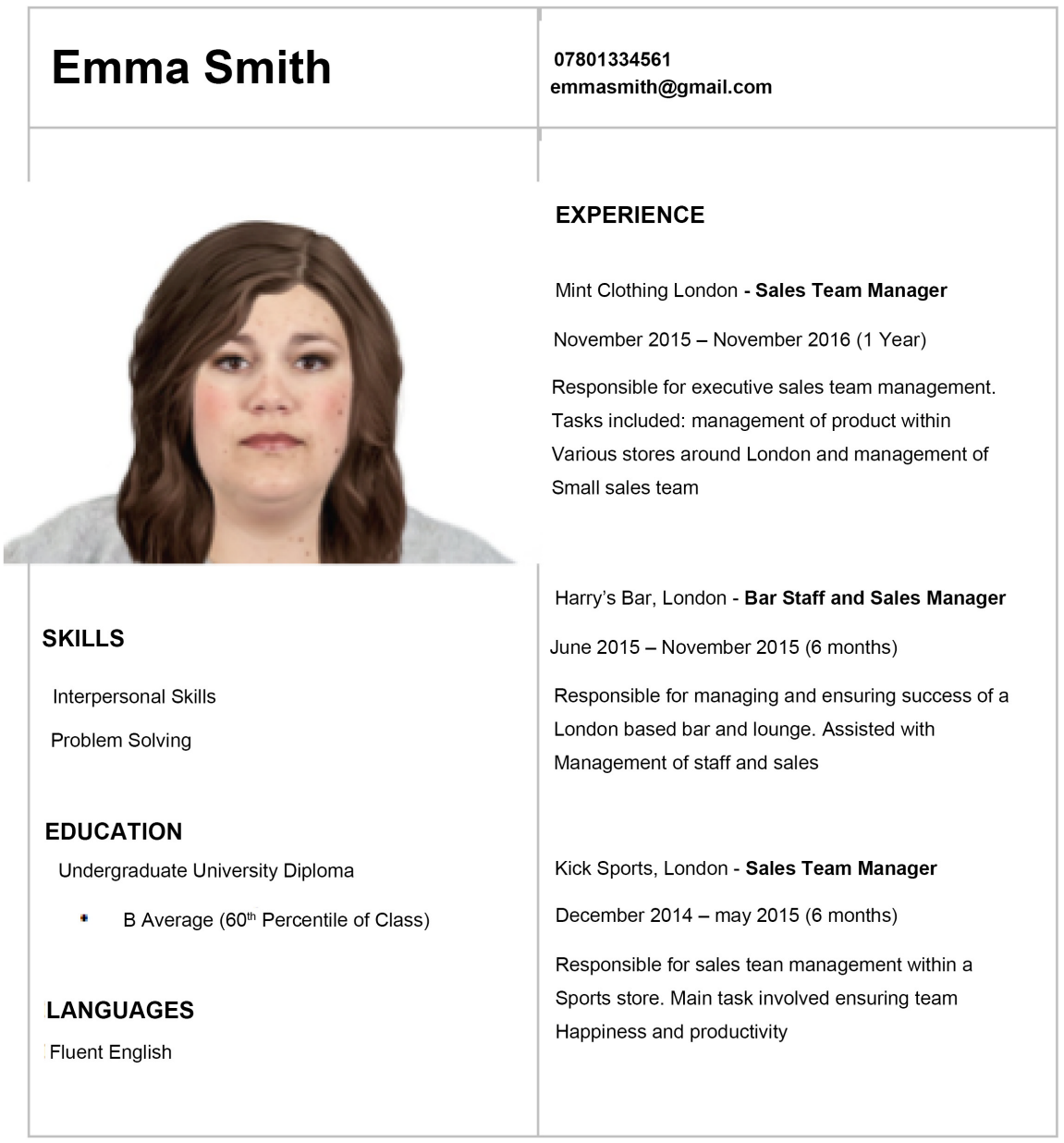

Figure A3. A copy of a resume. 